\title{
GANGGUAN MEMORI PADA PASIEN MENINGIOMA
}

\author{
Lalu Wisnu R Danu N, Anindhita Pangestika \\ Fakultas Kedokteran, Universitas Mataram, Indonesia \\ Email: laludanuu@gmail.com, anindhitap27@gmail.com
}

\begin{abstract}
Abstrak
Pasien tumor otak sering mengalami gangguan kognitif. Pada kasus meningioma, gangguan ini dapat menyerang area fungsi eksekutif dan memori. Gangguan kognitif pada pasien meningioma dipengaruhi oleh lokasi dan volume tumor. Dalam sebuah penelitian terhadap 38 pasien dengan meningioma derajat I WHO, kapasitas memori kerja lebih rendah pada pasien dengan reseksi tumor tanpa pengobatan adjuvant dibandingkan dengan kontrol yang sehat. Tujuan penelitian ini adalah untuk mengetahui ganngguan memori pada pasien meningioma. Penulisan artikel ini mencakup berbagai sumber yang berasal dari jurnal ilmiah dan pedoman pemerintah maupun instansi terkait. Pencarian sumber dilakukan di portal online publikasi jurnal seperti MedScape, Google Scholar (scholar.google.com) dan National Center for Biotechnology Information (ncbi.nlm.nih.gov), dengan kata kunci "Meningioma". Studi lain terhadap 293 pasien (220 wanita dan 73 pria) dengan multiple meningioma menunjukkan $23 \%$ pasien setelah operasi mengalami defisit neurologis dan $12 \%$ mengalami defisit neurologis permanen baru. Mengenai faktor risiko, satu penelitian menunjukkan bahwa frekuensi wanita lebih tinggi daripada pria. Selain itu, usia juga dinilai berpengaruh pada penderita meningioma. Meningioma merupakan tumor otak intrakranial yang sering ditemukan pada usia dewasa. Defisit kognitif sering terjadi pada pasien tumor otak. Setidaknya satu area kognisi terganggu pada pasien tumor otak.
\end{abstract}

Kata Kunci: Meningioma, Defisit Kognitif; faktor risiko

\section{Abstract}

Brain tumor patients often experience cognitive impairment. In the case of meningiomas, this disorder can affect areas of executive function and memory. Cognitive impairment in meningioma patients is influenced by the location and volume of the tumor. In a study of 38 patients with WHO grade I meningiomas, working memory capacity was lower in patients with tumor resection without adjuvant treatment compared with healthy controls. The writing of this article includes various sources originating from scientific journals and government guidelines and related agencies. Source searches were carried out on online portals for journal publications such as MedScape, Google Scholar (scholar.google.com) and the National Center for Biotechnology Information (ncbi.nlm.nih.gov), with the keyword "Meningioma". Another study of 293 patients (220 women and 73 men) with multiple meningiomas showed that $23 \%$ 
of patients after surgery had neurological deficits and $12 \%$ had new permanent neurological deficits. Regarding risk factors, one study showed that the frequency of women is higher than that of men. In addition, age is also considered to have an effect on patients with meningiomas. Meningiomas are intracranial brain tumors that are often found in adults. Cognitive deficits are common in brain tumor patients. At least one area of cognition is impaired in brain tumor patients.

Keywords: Meningioma, Cognitive Deficit; risk factors

Diterima: 13-11-2021

Direvisi: 11-12-2021

Diterbitkan: 20-12-2021

\section{Pendahuluan}

Meningioma merupakan tumor intrakranial primer yang paling umum ditemukan pada usia dewasa yang mewakili dari sepertiga semua neplasma intrakranial (Buerki et al., 2018; Huntoon, Toland and Dahiya, 2020). Meningioma adalah tumor jinak sistem saraf pusat yang biasanya timbul dari meninges otak dan sumsung tuang belakang (Alruwaili and Jesus, 2021).

Diperkirakan pada tahun 2015 insidensi tumor otak sebesar 10,82 per 100.000 orang pertahun hal ini meningkat dari periode tahun 2010 hingga 2014 dengan insidensi sebesar 8,3 per 100.000 orang pertahun (Alruwaili and Jesus, 2021). Di Amerika Serikat, Sekitar $37 \%$ dari semua tumor sistem saraf disebakan oleh meningioma. Insiden ini meningkat seiring bertambahnya usia (terutama diatas 65 tahun) dan dua kali lebih umum terjadi pada wanita dibandingkan dengan pria (Shaikh, Dixit and Raizer, 2018). Meningioma juga diketahui merupakan tumor jinak otak paling umum, sekitar $13 \%$ hingga 26\% dari seluruh tumor intrakranial (Saha, Jakhar and Kumar, 2016).

Kebanyakan meningioma bersal dari sporadis namun telah dikaitkan dengan kondisi dan faktor resiko tertentu. Faktor lingkungan seperti paparan radiasi pengion, radioterapi, paparan hormon eksogen, terapi pergantian hormonal, pengguanaan pil kontrasepsi oral, obesitas, alkoholisme dan kenker payudara dapat meningkatakan resiko terjadinya meningioma (Alruwaili and Jesus, 2021). Meningioma dapat timbul dari permukaan dural intrakranial atau spinal. Gejala klinis seperti sakit kepala, defisit neurologis lokal, kejang umum dan pasrial, perubahan kepribadian, kebingungan dan tingkat kesadaran yang berubah dapat terlihat pada pasien meningioma. (Saha, Jakhar and Kumar, 2016; Buerki et al., 2018).

Defisit kognitif umum terjadi pada pasien tumor otak. Setidaknya pasien dengan tumor otak menunjukan gangguan pada satu area kognisi. Gangguan paling umum terjadi pada domain fungsi eksekutif (78\%), sedangakan gangguan memori dan perhatiann adalah yang paling umum kedua (68\%) (Saha, Jakhar and Kumar, 2016). Fungsi kognitif ini berkaitan pada proses mental seperti perhatian, persepsi, pemikiran, penalaran dan mengingat sehingga terdapat tiga gejala umum yang dapat terlihat pada pasien meningioma yaitu nyeri kepala, perubahan status mental dan paresis (Coomans et al., 2019). Beberapa penelitian menyebutkan terjadinya gangguan memori pada 
pasien meningioma (Gondar et al., 2021). Pada penelitian lain juga ditemukan terjadinya gangguan neurokognitif yang cukup besar terutama bagian memori, perhatian dan fungsi eksekutif (Nassiri et al., 2020). Oleh karena itu banyak pasien meningioma yang pada awalnya didiagnosis sebagai depresi atau demensia (Buerki et al., 2018).

\section{Definisi}

Meningioma merupakan salah satu patologi yang umum dijumpai di sistem saraf pusat (SSP). Meningioma ini muncul dari lapisan arachnoid yaitu dari sel meningothelial, meningioma dapat terjadi dimana saja mulai dari bagian otak sampai dengan tulang belakang. Meningioma sering dinamai berdasarkan lokasi anatomisnya, misalnya meningioma yang berbatasan dengan tulang sphenoid antara lobus frontal dan temporal disebut sphenoid ridge meningioma. Biasanya meningioma bersifat jinak dan menyebabkan sedikit gejala sampai ukuran yang besar bisa juga menjadi ganas. Karena laju pertumbuhan tumor yang lambat, meningioma yang ditemukan secara kebetulan mungkin tidak memerlukan pengobatan selain tindak lanjut berkala. Untuk meningioma simptomatik, neoplasma ekstra-aksial intradural dapat ditangani dengan reseksi bedah bila menghasilkan efek massa yang signifikan atau dapat dikelola dengan bedah radio jika diameter maksimalnya $<3 \mathrm{~cm}$. Dengan kemajuan teknologi citra modern (misalnya citra resonansi magnetik), praktik bedah saraf kontemporer biasanya memperoleh hasil yang baik dalam pengobatan meningioma (Wu, 2014)

\section{Etiologi}

Etiologi dari meningioma belum dapat dipastikan namun diduga faktor genetik memiliki hubungan dengan kejadian meningioma dan radiasi serta hormon seks sebagai faktor resiko. Studi epidemiologi telah menunjukkan tingkat prevalensi yang lebih tinggi meningioma pada wanita. Faktor genetik terkait dengan mutasi genetik berupa inaktivasi gen NF 2 pada kromosom 22q sering dikaitkan dengan kejadian meningioma, sedangkan tipe $1 \mathrm{NF}$ tidak terkait. Penyebab lingkungan, radiasi pengion, dan hormon eksogen juga telah berkorelasi dengan meningioma intrakranial dalam beberapa penelitian sebelumnya (Wu, 2014)

\section{Faktor risiko}

Faktor risiko yang dapat menyebabkan meningioma adalah faktor usia, selain faktor bertambahnya usia, faktor lain yang berhubungan dengan risiko meningioma adalah paparan radiasi pengion. Faktor lingkungan, gaya hidup dan genetik lainnya telah diteliti dimana hasil yang tidak meyakinkan. faktor risiko yang telah dipelajari adalah penggunaan hormon endogen dan eksogen, penggunaan ponsel dan varian genetik atau polimorfisme Faktor risiko lain termasuk kondisi yang sudah ada sebelumnya (seperti diabetes, hipertensi, dan epilepsi), paparan timbal dalam pekerjaan, penggunaan pewarna rambut pribadi, paparan medan elektromagnetik frekuensi radio / gelombang mikro, trauma kepala, merokok dan alergi. Trauma kepala diduga sebagai faktor risiko meningioma sejak zaman Harvey Cushing, meskipun hasil penelitian tidak konsisten. Sementara beberapa studi kasus / kontrol kecil melaporkan peningkatan risiko meningioma terkait dengan trauma kepala untuk pria dan wanita. Untuk sebagian 
besar faktor ini, tidak ada hubungan yang signifikan atau hubungan yang tidak konsisten dengan risiko meningioma yang telah dilaporkan. Banyak dari studi ini memiliki ukuran sampel yang kecil, waktu tindak lanjut yang singkat, dan perbedaan dalam kriteria kelayakan dan pengukuran keterpaparan, membuat reproduktifitas di seluruh studi menjadi sulit (Wiemels, Wrensch and Claus, 2010; Niban GM, Ganapathy Vel Kannan M, Sudhakar K, 2017)

\section{Patofisiologi sindrom gangguan memory pada meningioma}

Faktor yang mungkin mempengaruhi fungsi kognitif pada pasien meningioma adalah lokasi dan volume tumor. Berdasarkan lokasi, meningioma pada sisi kiri secara signifikan dikaitkan dengan memori verbal yang lebih rendah dibandingkan dengan meningioma sisi kanan. Fungsi eksekutif lebih rendah pada pasien dengan meningioma pada lobus frontal (Bragt, 2018). Sebagai contoh, pada pasien meningioma frontal, terdapat gangguan pra-operasi yang signifikan pada pasien pada pengukuran memori kerja, perhatian, dan fungsi eksekutif rata-rata yang lebih rendah dibandingkan dengan kelompok kontrol yang sehat. Setelah operasi, perbaikan signifikan diamati pada ukuran memori dan perhatian (Meskal et al., 2016).

Selain lokasi tumor, volume tumor juga menjadi faktor yang mempengaruhi fungsi kognitif pada pasien meningioma. Volume meningioma secara langsung mempengaruhi jaringan otak disekitarnya karena meningioma tumbuh di dalam membrane di sekitar sistem saraf pusat, tetapi mereka terletak berdekatan dengan korteks otak, di mana kognitif fungsi berada. Selain itu, meningioma secara tidak langsung menyebabkan peningkatan tekanan intrakranial karena rasio antara massa otak dan ukuran otak meningkat. Hal ini didukung oleh penelitian yang dilakukan Grujicic dkk. (2017) yang menemukan tanda-tanda peningkatan intrakranial tekanan pada 83,3\% pasien meningioma. Gangguan kognitif yang lebih banyak ditemukan pada pasien dengan volume meningioma lebih besar (Bragt, 2018).

\section{Epidemiologi}

Meningiona nerupakan tumor yang paling umum di system saraf pusat pada

orang dewasa (Marchand et al., 2014). Studi berbasis rumah sakit telah menemukan bahwa 20\% dari keseluruhan tumor otak primer adalah meningioma (Saraf et al., 2011). Selama beberapa dekade terakhir peningkatan dan penggunaan pencitaraan otak yang lebih sering telah menghasilkan peningkatan insiden diagnostik dan prevalensi meningioma. Berdasarkan United States Central Brain Tumor Registry, meningioma memiliki insiden tertitinggi dan mencapai 35,5\% dari seluruh tumor otak primer pada periode antara 2005 dan 2009 (Saraf et al., 2011).

\section{Manifestasi klinis}

Gejala yang paling umum dilaporkan adalah sakit kepala, gangguan penglihatan dan anosmia, seringkali menyebabkan kesalahan diagnosis seperti sinusitis, migrain dan neuralgia. Dalam sebuah studi pada kasus meningioma alur olfaktorius, skrining tanda dan gejala pra operasi mengungkapkan adanya perubahan mental, sakit kepala, gangguan penglihatan, pusing, kejang (seizure), papilledema dan hemiparesis 
(Marchand et al., 2014). Tanda dan gejala lain yang dapat ditemukan adalah muntah, proptosis, ataxia, cranial nerve palsy, dan gangguan berbicara (Samadi et al., 2007).

\section{Tatalaksana}

Pengobatan yang sering digunakan pada pasien tumor yaitu kombinasi dari pembedahan, radioterapi, kemoterapi, dan pengobatan suportif (Coomans et al., 2019)

1. Operasi

Umumnya pasien dengan tumor otak mengalami lebih sedikit kejang, sakit kepala dan tanda-tanda tekanan intrakranial setelah operasi.

2. Radioterapi

Radiasi dapat menyebabkan cacat kognitif yang signifikan, tetapi sebagian besar bersifat sementara pada sekitar 50-90\% pasien. Efek samping akut dari radioterapi adalah peradangan dan cedera pada struktur saraf, yang menyebabkan edema sehingga menimbulkan gejala seperti sakit kepala, mual, pusing, serta defisit kognitif. Efek early-delayed (efek pada bulan-bulan pertama setelah radiasi) seperti demielinasi dan edema yang dapat mempengaruhi fungsi kognitif juga.

3. Kemoterapi

Agen kemoterapi dapat menyebabkan defisit kognitif baik jangka pendek maupun jangkan panjang.

4. Pengobatan suportif

Pada pasien meningioma yang telah dilakukan pembedahan atau radioterapi ternyata masih ada yang menunjukkan penurunan fungsi kognitif termasuk memori sehingga dibutuhkan terapi lanjutan yang bersifat telerehabilitasi seperti (Linden et al, 2018):

\section{Remind}

Program telerehabiltasi kognitif remind merupakan aplikasi yang disediakan di iPad dan tersedia dalam 2 bahasa yaitu bahasa Inggris dan bahasa Belanda. Remind terdiri dari pelatihan kompensasi, termasuk psikoedukasi, dan keterampilan kompensasi. Dalam pelatihan kompensasi, psikoedukasi tentang fungsi kognitif diberikan 6 modul dan dalam setiap modul diajarkan strategi kompensasi dan diberikan latihan untuk diterapkan di kehidupan sehari-hari seperti meminimalkan gangguan.

2. C-Car

Pada $C$-Car diberikan 4 mode yang mencakup latihan visual dan pendengaran. Semua pasien memulai dengan versi yang sama, terlepas dari skor neuropsikologis pra-intervensi mereka. Setelah selesai latihan pasien akan mendapatkan umpan balik tentang kinerja mereka. Teks instruksional dari pelatihan strategi disediakan dalam bentuk video, audio dan hanya membaca format yang disediakan 


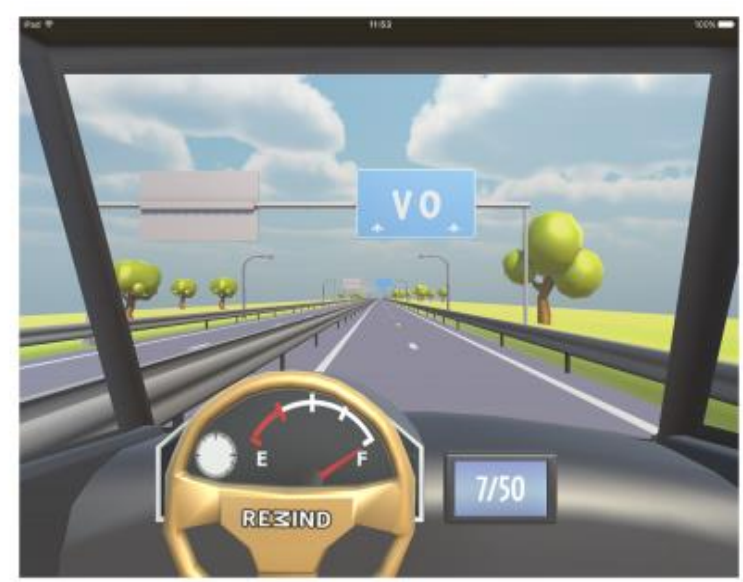

\section{Fungsi kognitif}

Fungsi kognitif adalah istilahyang mengacu pada proses mental yang terlibat dalam akusisi pengetahuan, manipulasi informasi, dan pertimbangan atau pemikiran. Pada fungsi kognitif memiliki beberpa domain seperti domain persepsi, memori, pembelajaran, perhatian, pengambilan keputusan, dan kemampuan Bahasa (Kiely, 2014)

Penelitian di eropa menunjukkan prevalensi gangguan kognitif berkisar antara 5,1-24,5\% sementara di amerika utara, diperkirakan prevalensi gangguan berkisar 13,828,3\%. Insiden gangguan kognitif di Eropa berkisar antara 56-76 dari 1000 orang pertahun sementara di amerika utara prevalensisnya berkisar 41-65 dari 1000 orang pertahun (Pais et al., 2020)

Beberapa faktor yang bisa mempengaruhi fungsi kognitif yang telah teridentifikasi seperti usia, pendidikan jenis kelamin, factor kesehatan seperti minum alkohol, merokok, dan depresi untuk factor social seperti pekerjaan dan aktifitas social, riwayat penyakit, dan indeks masa tubuh (BMI) bisa menjadi factor yang memepengaruhi fungsi kognitif. faktor yang konsisten dilaporkan sebagai gangguan kognitif seperti usia, pendidikan, dan depresi (Kim, M. and Park, J.-M., 2017).

\section{Memori}

Memori adalah penyimpanan pengetahuan yang didapat sebelumnya dan bisa diingat kembali. Belajar dan mengingat adalah dasara bagi suatu individu untuk beradaptasikan perilaku mereka terhadap suatu lingkungan. Tanpa adanya mekanisme ini seseorang tidak bisa merencanakan interaksi dan tidak bisa dengan sengaja menghindari keadaan-keadaan yang tidak diinginkan dan seharusnya bisa diprediksi. Perubahn saraf yg memiliki peran dalam penyimpanan pengetahuan disebut dengan jejek memori (memory traces). Pada penyimpanan informasi dapat dilakukan dengan dua cara yaitu ingatan jangka pendek dan ingatan jangka panjang. Pada ingatan jangka pendek hanya berlangsung hanya beberapa detik sampai jam, sementara pada ingatan jangka panjang bisa dipertahankan selama beberapa hari sampai bertahun-tahun. Untuk pemindahan dan fiksasi ingatan jangka pendek menjadi ingatan jangka panjang dengan melalu proses konsolidasi. Informasi yang baru diterima tersimpan pada memori jangka 
pendek yang memiliki kapasitas penympanan yang terbatas. informasi yang baru tersimpan di memori jangka pendek akan mengalami dua hal yaitu informasinya akan dilupakan misalnya nomer telepon yang baru dilihat atau pindah ke ingatan jangka panjang yang permanen melalui latihan aktif atau pengulangan. Kapasitas penyimpanan untuk ingatan jangka panjang lebih besar dimana informasi yang sudah tersimpan akan diproses, dikodifikasi, dan kemudian disimpan denagn ingatan yang sama; misalnya seperti ingatan visual yang akan tersimpan terpisah dengan ingatan pendengaran dan untuk memudahkan pencarian ingatan yang diinginkan. Neuron-neuron yang berperan dalam jejak ingatan tersebar diseluruh daerah subkorteks dan korteks otak dan bagian otak yang paling berperan dalam ingatan adalah hipokampus, struktur pada lobus temporalis medial, sistem limbik, sereblum, kortek prafrontalis, dan bagian lain korteks serebrum (Sherwood, 2013).

Hipokampus merupakan tempat penyimpanan ingatan jangka panjang yang baru dan hanya sesaat kemudian dipindahkan ke bagian korteks yang lain untuk penyimpanan yang lebih permamen. Hipokampus dan daerah sekitarnya berperan penting dalam ingatan deklaratif yaitu ingatan tentang orang, tempat, benda, fakta, dan kejadian yang spesifik. Ingatan deklaratif memerlukan pemanggilan kembali secara sadar dan kadang dibagi menjadi ingatan semantik (ingatan tentang fakta) dan ingatan episodik (ingatan tentang kejadian sehari-hari). Seseorang dengan kerusakan hipokampus akan mudah lupa dengan fakta-fakta yang penting dalam kehidupan seharihari, dan biasanya ingatan yang pertama kali hilang adalah ingatan deklaratif (Sherwood, 2013).

Serebeblum dan daerah korteks berperan dalam ingatan prosedural yang melibatkan keterampilan motorik yang diproleh melalui latihan berulang, seperti mengingat gerakan tari tertentu. Ingatan prosedural dapat dilaksanakan tanpa upaya sadar, misalnya pada pemain ski yang ahli selama pertandingan bisa membiarkan tubuhnya mengambil alih tanpa memikirkan secara pasti gerakan yang harus dilakukan. Pada orang yang menalami lesi pada temporalis atau limbik bisa melakukan suatu keterampilan pada hari ini dan tidak akan mengingat kejadian sekarang pada keesokan harinya (Sherwood, 2013).

Korteks prafrontal yang berperan dalam kemampuan berfikir kompleks yang berkaitan dengan memori kerja adalah korteks asosiasi prafrontal. Fungsi korteks frontal adalah sebagai tempat penyimpanan sementara data-data yang relevan dan berperan besar dalam fungsi eksekutif yang melibatkan manipulasi dan integrasi informasi untuk perencanaan, memilih prioritas, membuat pilihan, pemecahan masalah, pengorganisasian aktivitas, dan penghambat implus. Fungsi eksekutif yaitu memungkinkan seseorang untuk memutuskan apa yang harus dilakukan dan bukan hanya bereaksi pada situasi saat itu. Korteks frontal bekerja sama dengan semua regio sensorik otak melalui koneksi-koneksi saraf (Sherwood, 2013).

\section{Berbagai Penelitian terkait gangguan memori pada pasien meningioma}

Sebanyak 38 pasien dengan fungsi kognitif pasien meningioma WHO grade I pada orang dewasa yang telah menjalani reseksi tumor tanpa pengobatan adjuvan 
memiliki kapasitas memori kerja yang jauh lebih rendah dibandingkan dengan control yang sehat. Tidak ada perbedaan yang signifikan secara statistic ditemukan antara pasien dan kontrol yang sehat dalam fungsi eksekutif, memori verbal, fungsi perhatian, kecepatan pemerosesan informasi, atau kecepatan psikomotor. Penurunan kinerja memori ini dikaitkan dengan konektivitas fungsional yang lebih rendah di Default Mode Network (DMN) dan tingkat maksimum Minimum Spanning Tree (MST) yang lebih rendah di pita teta (Nieuwenhuizen et.al, 2018).

Semua pasien menunjukkan secara signifikan buruk $(\mathrm{p}<0,05)$ pada sebagian besar neurokognitif. Defisit verbal lebih terlihat pada bagian hemisphere kiri dibandingkan hemisphere kanan. Pasien deng tumor berukuran besar $(>4 \mathrm{~cm})$ memiliki defisit neurokognitif yang lebih parah dibandingkan dengan tumor kecil $(<4 \mathrm{~cm})$. Pasca operasi, pasiem tidak menunjukkan penurunan fugsi neurokognitif. Sebaliknya, peningkatan yang signifikan $(\mathrm{P}<0,05)$ diamati pada beberapa fungsi korteks asosiasi eksekutifm motorik dan parietal (Liouta et al., 2016).

Meningioma umunya tumbuh lambat dan persentase mereka terutama disebabkan oleh kompresi struktur didekatnya. Tiga gejala yang paling umum ditemukan antara lain, depresi deficit memori, dan sifat agresif yang ditemukan pada pasien rawat inap dengan tumor otak. Ketika meningioma mengenai bagian lobus frontal, gejala kelesuan, apatis, psikomotor melambat, dan gangguan konsentrasi mungkin secara historis tidak dapat dibedakan dari episode afektif. Dalam kasus ini, meningioma pasien berada di dekat Sphenoid wing, mengenai lobus frontal, sehingga gejala kognitif merupakan ciri-ciri yang muncul. Pasien penelitian ini memperlihatkan ciri khas dari executive dysfunction syndrome: ciri ciri utama dengan fitur gangguan penalaran, pemecahan masalah dan penilaian yang menyebabkan gangguan fungsi sosial dan pekerjaan, yang selanjutnya menimbulkan gangguan bagi pasien dan keluarganya. Dengan demikian, individu yang menunjukkan gejala demensia sebelum usia 50 tahun harus dinilai dengan cermat sebelum diberikan diagnosis pasti karena tumor intrakranial primer tidak menghasilkan manifestasi klinis spesifik yang memudahkan diagnosisinya. Alasan pertama peneliti mencurigai penyebab medis untuk demensia pada pasien ini adalah onset usia dini (kurang dari 45 tahun), gangguan intelektual yang signifikan, kehilangan memori, kesulitan menangani uang, membuat kesalahan di tempat kerja, penyangkalan, penarikan sosial, dan signifikan. gangguan dalam fungsi sosial dan pekerjaan. Sangat sulit untuk mendekati pasien dengan temuan yang menunjukkan demensia dini, tetapi pengenalan gejala awal membantu dalam diagnosis dan manajemen dini (Saha et al, 2016).

Sebanyak 293 pasien dengan multiple meningioma dianalisis, 220 wanita dan 73 pria, dari 932 total tumor. mayoritas tumor terletak di konveksitas yaitu (65,3\% sampai $74,5 \%)$. Jumlah total tumor yang diobati adalah sebanyak 429 (43,9\%). dari 338 $(78,8 \%)$ dilakukan dengan cara reseksi bedah dan $91(21,2 \%)$ dengan cara radioterapi. Deskripsi histopatologi tersedia pada 303 dari 429 kasus menjadi derajat I pada 272 $(90,3 \%)$ kasus dengan dominasi subtipe meningotelial $(30,7 \%)$. Kekambuhan tumor 
dijelaskan pada 32 pasien $(8,07 \%)$ di antara 397 dan hanya 10 kasus kematian $(3,4 \%)$ dari 281 kasus yang dilaporkan, di mana karakteristik ini dievaluasi (Araújo et al, 2019)

Setelah operasi menunjukkan $23 \%$ mengalami deficit neurologis sementara dan pada $12 \%$ pasien menunjukkan kondisi defisit neurologi baru yang permanen dengan berbagai tingkatan manifestasi. Kualitas hidup pasca operasi tetap stabil dan sedikit membaik pada pemeriksaan lanjut pada T3 (60,6 $\pm 21,5$ vs 63,6 $\pm 24,1$ poin), dan tidak ada efek pada kecemasan maupun depresi. Pada bulan pertama setelah operasi sedikit mempengaruhi memori jangka panjang, memori kerja, dan fungsi eksekutif dan tampaknya paling rentan terhadap gangguan reseksi maupun tumor, tetapi pada sebagian pasien satbil mapun membaik setelah pemeriksaan tindak lanjut jangka panjang setelah 1 tahun. (Zweckberger, K. et al., 2017).

Meskipun meningioma adalah tumor jinak, namun meningioma menyebabkan dampak yang signifikan bagi pasien dan dapat menjadi tantangan bagi dokter dalam pengawasan dan manajemen yang sedang berlangsung. Reseksi bedah tetap menjadi standar emas bila GTR dapat dicapai. Pada beberapa kasus seperti reseksi maksimal tidak dapat diperoleh dengan aman, kasus yang tidak dapat dioperasi, sisa tumor tetap ada, dan / atau tumor merupakan lesi tingkat tinggi yang agresif, terapi adjuvan diperlukan. Seperti yang telah diulas, ditemukan adanya kekurangan dari terapi adjuvan ini dan beberapa terapi sistemik telah disetujui atau terbukti efektif. Penelitian dan uji klinis yang sedang berlangsung akan diperlukan untuk mengatasi kesenjangan pengobatan ini. (Huntoon, K. Et al., 2020)

Pada suatu penelitian terdapat frekuensi perempuan yang lebih tinggi dibandingkan dengan laki-laki. Lokasi tumor primer pada konveksitas pada $42 \%$, tentorium/falx pada $29 \%$, dasar tengkorak pada $19 \%$, dan infratentorial pada $10 \%$. Meningioma diidentifikasi pada 2,2\% peserta dalam sampel berbasis populasi yang Sebagian adalah orang dewasa. Salah satu faktor risiko yang diketahui adalah usia, tetapi tidak secara signifikan terkait dengan meningioma pada sampel yang lebih tua di mana usia rata-rata adalah 75,6 tahun (Cerhan et al., 2019).

BMI merupakan temuan konsisten dalam penelitian ini dan merupakan factor risiko yang berpotensi dapat dimodifikasi. Beberapa subjek penelitian dengan meningioma iani mengalami sakit kepala atau gejala lain yang terkait dengan meningioma yang ditangani dnegan obat analgesic (Cerhan et al., 2019).

Seorang wanita berusia 52 tahun, sudah menikah, merupakan seniman dengan tangan kanan di sekolah menengah atas. Pasien menunjukkan gambaran klinis trauma kepala tanpa kehilangan kesadaran disertai sakit kepala yang terus-menerus. Radiografi sinus paranasal diambil dan menunjukkan hasil yang normal. Pemindaian otak menunjukkan meningioma 2,7 $\times 2,4 \mathrm{~cm}$ terletak di daerah frontoparietal sinistra dengan hiperostosis (Hurtado-Gonzalez, C. A., et al., 2017).

Dalam pemeriksaan neurologis pasien dalam keadaan sadar, waspada dan berorientasi pada bidang temporal dan spasial. Pada pemeriksaan fisik ditemukan tekanan darah 120/80 mmHg, nadi 80 / mnt, frekuensi pernapasan-20/mnt. Reseksi tumor (meningioma frontoparietal) dilakukan. Dalam riwayat kesehatan tidak ada 
laporan komplikasi selama operasi. Hasil klinis memuaskan tanpa terlihat jelas defisit neurologis. Pasien waspada, berorientasi dan ekspresif. Manajemen pasca bedah dimulai dengan Fenitoin $100 \mathrm{mg}$ setiap 8 jam dan Cephalexin $500 \mathrm{mg}$ setiap 6 jam selama 7 hari untuk mencegah infeksi pada luka operasi, dan Acetaminophen $500 \mathrm{mg}$ (2 tablet setiap 6 jam selama 15 hari). Pada tingkat emosional, pasien tidak menunjukkan gejala klinis gambar depresi, kecemasan dan sikap apatis. (Hurtado-Gonzalez, C. A., et al., 2017).

Protokol evaluasi neuropsikologis diaplikasikan dengan tes MMSE (Minimental state examination), tes rentang digit, TMT (Trail making test), tes mengingat cerita Babcock, tes figur kompleks Rey-Osterrieth, clock test, tes memori, FAB (frontal assessment battery) dan test kefasihan verbal. Hasil menunjukkan bahwa pasien mengalami kesulitan untuk menangani informasi langsung, terkait dengan kemungkinan disfungsi lobus frontal (memori kerja), ketidakmampuan untuk mengingat materi yang diberikan melalui pendengaran (memori verbal tertunda). Ditemukan bahwa pasien tidak dapat membentuk kata kerja atau alternasi kata yang sama (fungsi Eksekutif), ini mempengaruhi kualitas hidupnya pada tingkat yang lebih rendah. (Hurtado-Gonzalez, C. A., et al., 2017)

Studi ini menyelidiki kumpulan data Rumah Sakit Elisabeth-TweeSteden / Universitas Tilburg pasien meningioma. Fungsi kognitif dan efek lokalisasi (tumor sisi kiri versus sisi kanan, frontal versus non-frontal dan temporal versus non-temporal) dan volume tumor diselidiki. 223 Pasien dirawat di baterai tes neuropsikologi CNS Vital Signs di empat momen tes: sebelum operasi dan 3, 12 dan 24 bulan setelah operasi (t0, t3, t12 dan t24). Tujuh domain kognitif yang berbeda diperiksa (Bragt, 2018).

Hasil penelitian menunjukkan bahwa fungsi kognitif pada pasien meningioma secara signifikan terganggu ketujuh domain di t0, t3 dan t12, dibandingkan dengan kontrol Belanda yang sehat ( $\mathrm{p}<.01$ ). Di t24, pasien skor kecepatan psikomotorik, kecepatan proses dan memori verbal masih terganggu secara signifikan (hal <.05). Sedikit bukti untuk efek lokasi tumor pada fungsi kognitif ditemukan. Tumor volume berkorelasi dengan fungsi kognitif pada 0 ( $\mathrm{r}=-.164$ hingga $-.315, \mathrm{p}<.05)$ dan fungsi kognitif peningkatan dari t0 ke t3 $(r=.208$ menjadi $.384, p<.01)$ pada semua domain kognitif kecuali untuk verbal Penyimpanan. Studi ini menunjukkan bahwa meningioma menyebabkan kerusakan serius pada fungsi kognitif. Pasien dengan tumor yang lebih besar mendapat skor lebih rendah pada tes kognitif, tetapi menunjukkan pemulihan lebih setelahnya operasi. Dokter dapat menggunakan informasi ini untuk memberikan perawatan kesehatan meningioma secara lebih memadai pasien yang menjalani operasi (Bragt, 2018).

Berdasarkan beberapa penelitian di atas gangguan sindrom memori ditemukan memiliki kapasitas memori kerja yang jauh lebih rendah. Defisit verbal lebih terlihat pada bagian hemisphere kiri dibandingkan hemisphere kanan, depresi deficit memori, sifat agresif, kelesuan, apatis, psikomotor melambat, dan gangguan konsentrasi, gangguan penalaran, pemecahan masalah dan penilaian yang menyebabkan gangguan fungsi sosial dan pekerjaan, yang selanjutnya menimbulkan gangguan bagi pasien dan keluarganya, kesulitan untuk menangani informasi langsung, terkait dengan 
kemungkinan disfungsi lobus frontal (memori kerja), ketidakmampuan untuk mengingat materi yang diberikan melalui pendengaran (memori verbal tertunda), dan tidak dapat membentuk kata kerja atau alternasi kata yang sama (fungsi eksekutif),

\section{Kesimpulan}

Meningioma merupakan tumor otak pada daerah intrakranial yang umum ditemukan pada usia dewasa yang mewakili sepertiga dari seluruh neplasma intracranial. Gangguan yang umum terjadi pada tumor otak dapat berupa defisit kognitif, setidaknya pasien dengan tumor otak menunjukkan adanya gangguan pada salah satu area kognisi. Paling sering terjadi pada domain fungsi eksekutif, kemudian diikuti oleh gangguan memori dan perhatian. Penyebab terjadinya meningioma masih belum dapat dipastikan, namun terdapat beberapa faktor risiko yang mempengaruhi seperti usia, pengaruh radiasi pengion, lingkungan, gaya hidup dan genetik. Pengobatan yang dapat dilakukan pada pasien tumor yaitu kombinasi dari pembedahan, radioterapi, kemoterapi, dan pengobatan suportif.

Pada pasien meningioma yang telah dilakukan pembedahan atau radioterapi tetapi masih menunjukkan penurunan fungsi kognitif termasuk memori, maka dibutuhkan terapi lanjutan yang bersifat telerehabilitasi seperti remind dan c-car. Dari beberapa penelitian terkait gangguan memori pada pasien meningioma didapatkan bahwa gangguan sistem memori ditemukan memiliki kapasitas memori kerja yang jauh lebih rendah, defisit verbal lebih tampak pada hemisfere kiri serta adanya gangguan fungsi eksekutif.

Diagnosa cepat dan tepat pada pasien meningioma perlu dilakukan, sehingga dapat diupayakan rencana pengobatan yang optimal dengan tujua mencegah terjadinya gangguan neuropsikologi pada pasien. 


\section{BIBLIOGRAFI}

Alruwaili, A. A. and Jesus, O. De (2021) Meningioma - StatPearls - NCBI Bookshelf. Available at: https://www.ncbi.nlm.nih.gov/books/NBK560538/ (Accessed: 20 April 2021).

Araújo Pereira, B. J. et al. (2019) 'Multiple Intracranial Meningiomas: A Case Series and Review of the Literature', World Neurosurgery, 122, pp. e1536-e1541. doi: 10.1016/j.wneu.2018.11.097. Google Scholar

Bragt, Y. J. . (2018) 'Cognitive functioning in meningioma patients and the effects of tumor location and tumor volume', pp. 1-22.

Buerki, R. A. et al. (2018) 'An overview of meningiomas', Future Oncology. Future Medicine Ltd., pp. 2161-2177. doi: 10.2217/fon-2018-0006. Google Scholar

Cerhan, J. H. et al. (2019) 'Factors Associated with Meningioma Detected in a population Based Sample', HHS Public Access, 94(2), pp. 254-261. doi: 10.1016/j.mayocp.2018.07.026.Factors. Google Scholar

Coomans, M. B. et al. (2019) 'Treatment of cognitive deficits in brain tumour patients: current status and future directions', Current Opinion in Oncology, 31(6), pp. 540-547. doi: 10.1097/cco.0000000000000581. Google Scholar

Gondar, R. et al. (2021) 'Meningiomas and Cognitive Impairment after Treatment: A Systematic and Narrative Review', Cancers, 13(8), p. 1846. doi: 10.3390/cancers13081846. Google Scholar

Hurtado-Gonzalez, C. A., et al., (2017), Neuropsychological abnormalities in a patient diagnosed with frontoparietal meningioma, Biomedical Research, vol. 28(2)

Huntoon, K., Toland, A. M. S. and Dahiya, S. (2020) 'Meningioma: A Review of Clinicopathological and Molecular Aspects', Frontiers in Oncology. Frontiers Media S.A. doi: 10.3389/fonc.2020.579599. Google Scholar

Jamshidi, S., Ensafi, M., \& Pati, D. (2020). Wayfinding in interior environments: An integrative review. Frontiers in Psychology, 11. https://doi.org/10.3389/fpsyg.2020.549628) Google Scholar

Kim, M. \& Park, J.-M., 2017. Factors affecting cognitive function according to gender in community-dwelling elderly individuals. Epidemiology and Health, 39 Google Scholar

Linden S.D. van der, Sitskoorn MM, Rutten GM, Gehring K. (2018) Feasibility of the evidence-based cognitive telerehabilitation program Remind for patients with primary brain tumors. J Neurooncol. May;137(3):523-532. doi: 10.1007/s11060-017-2738-8. Google Scholar

Liouta, E., Koutsarnakis, C., Liakos, F. and Stranjalis, G. (2016) 'Effects of intracranial meningioma location, size, and surgery on neurocognitive functions: a 3-year prospective study', J Neurosurg, 124, pp. 1578-1584. doi: 10.4135/9781412983907.n1537. Google Scholar 
Marchand, A. A. and O'Shaughnessy, J. (2014) 'Subtle clinical signs of a meningioma in an adult: A case report', Chiropractic and Manual Therapies, 22(1), pp. 1-5. doi: 10.1186/2045-709X-22-8. Google Scholar

Nassiri, F. et al. (2020) 'How to live with a meningioma: experiences, symptoms, and challenges reported by patients', Neuro-Oncology Advances, 2(1), pp. 1-10. doi: 10.1093/noajnl/vdaa086. Google Scholar

Niban GM, Ganapathy Vel Kannan M, Sudhakar K, M. G. (2017) 'Evaluation of risk factors influencing surgical outcome in meningiomas with CLASS algorithm', International Journal of Scientific Study, 4(12), pp. 94-98. doi: 10.17354/ijss/2017/105.

Nieuwenhuizen, D., Douw, L., Klein, M., Peerdeaman, S., \& et.al. (2018). Cognitive Functioning and Functional Brain Networks in Postoperative WHO Grade I Meningioma Patients. Journal of Neuro-Oncology, 605-613.

Pais, R. et al., 2020. Prevalence and incidence of cognitive impairment in an elder Portuguese population (65-85 years old). BMC Geriatrics, 20(1). Google Scholar

Samadi, N. and Ahmadi, S. A. (2007) 'Meningioma: A Clinicopathological Evaluation', Malaysian Journal of Medical Sciences, 14(1), pp. 46-52. Google Scholar

Saha, R., Jakhar, K. and Kumar, R. (2016) 'Sphenoid wing meningioma presenting as cognitive impairment', Shanghai Archives of Psychiatry, 28(3), pp. 173-176. doi: 10.11919/j.issn.1002-0829.215142. Google Scholar

Saraf, S., McCarthy, B. J. and Villano, J. L. (2011) 'Update on Meningiomas', The Oncologist, 16(0), pp. 1604-1613. doi: 10.1634/theoncologist.2011-0227. Google Scholar

Shaikh, N., Dixit, K. and Raizer, J. (2018) 'Recent advances in managing/understanding meningioma [version 1; referees: 2 approved]', F1000Research. F1000 Research Ltd. doi: 10.12688/f1000research.13674.1. Google Scholar

Sherwood L. 2013. Introduction to human physiology. 8th ed. Canada: Nelson education, Ltd. p. 165, 204-206. Google Scholar

Wiemels, J., Wrensch, M. and Claus, E. B. (2010) 'Epidemiology and etiology of meningioma', Journal of Neuro-Oncology, 99(3), pp. 307-314. doi: 10.1007/s11060-010-0386-3. Google Scholar

$\mathrm{Wu}$, J. C. (2014) 'Risk factors of meningioma', Journal of the Chinese Medical Association, 77(9), pp. 451-452. doi: 10.1016/j.jcma.2014.07.005. Google Scholar

Zweckberger, K. et al., 2017. Prospective analysis of neuropsychological deficits following resection of benign skull base meningiomas. Journal of Neurosurgery, 127(6), pp.1242-1248. Google Scholar 
First publication right:

Jurnal Syntax Fusion: Jurnal Nasional Indonesia

This article is licensed under:

(ㅇ) (1) ( $)$ 